\title{
CLINICALLY AGGRESSIVE CENTRAL GIANT CELL GRANULOMAS IN TWO PATIENTS WITH NEUROFIBROMATOSIS 1
}

Paul C. Edwards ${ }^{1}$ M.Sc., D.D.S., John E. Fantasia ${ }^{2}$ DDS, Tarnjit Saini ${ }^{3}$ DDS, MS, Tracey J. Rosenberg ${ }^{4}$ DDS, MD, Stephen A. Sachs ${ }^{5}$ DDS, and Salvatore Ruggiero ${ }^{6}$ DDS, MD.

${ }^{1}$ Assistant Professor, Division of Oral and Maxillofacial Pathology, Department of General Dentistry, Creighton University School of Dentistry, Omaha, NE,

${ }^{2}$ Chief, Division of Oral and Maxillofacial Pathology, Department of Dental Medicine, Long Island Jewish Medical Center, New Hyde Park, NY,

${ }^{3}$ Professor, Division of Oral and Maxillofacial Radiology, Department of General Dentistry, Creighton University School of Dentistry, Omaha, NE,

${ }^{4}$ Former Chief Resident, Department of Dental Medicine, Division of Oral and Maxillofacial Surgery, Long Island Jewish Medical Center, New Hyde Park, NY. Currently in Private Practice, Plainview, NY,and ${ }^{5}$ Attending, Division of Oral and Maxillofacial Surgery, Department of Dental Medicine, Long Island Jewish Medical Center, New Hyde Park, NY and Private Practice, Lake Success, NY, and

${ }^{6}$ Chief, Division of Oral and Maxillofacial Surgery, Department of Dental Medicine, Long Island Jewish Medical Center, New Hyde Park, NY.

Author's accepted manuscript; final version published as:

Edwards PC, Fantasia JE, Saini T, Rosenberg TJ, Sachs SA, Ruggiero S. Clinically aggressive central giant cell granulomas in two patients with neurofibromatosis 1. Oral Surg Oral Med Oral Pathol Oral Radiol Endod. 2006 Dec;102(6):765-72. 


\section{CLINICALLY AGGRESSIVE CENTRAL GIANT CELL GRANULOMAS IN TWO PATIENTS WITH NEUROFIBROMATOSIS 1}

Keywords: Central giant cell granuloma, neurofibromatosis 1, osseous changes, bone

Author's accepted manuscript; final version published as:

Edwards PC, Fantasia JE, Saini T, Rosenberg TJ, Sachs SA, Ruggiero S. Clinically aggressive central giant cell granulomas in two patients with neurofibromatosis 1. Oral Surg Oral Med Oral Pathol Oral Radiol Endod. 2006 Dec;102(6):765-72. 
Address reprint requests to:

Dr. Paul C. Edwards

Assistant Professor of Oral Pathology,

Department of General Dentistry,

Director, Surgical Oral Pathology Biopsy Service

Creighton University School of Dentistry,

2500 California Plaza,

Omaha, NE 68178

Tel: (402)-280-5025

Fax: (402)-280-5094

E-mail: pedwards@creighton.edu 


\section{Abstract}

Background: Neurofibromatosis 1 (NF1) is an autosomal dominantly inherited disorder caused by a spectrum of mutations affecting the $N f 1$ gene. Affected patients develop benign and malignant tumors at an increased frequency. Clinical findings include multiple café-au-lait cutaneous pigmentations, neurofibromas, axillary freckling, optic gliomas, benign iris hamartomas (Lisch nodules), scoliosis, and poorly defined soft tissue lesions of the skeleton. Kerl first reported an association of NF1 with multiple central giant cell granulomas (CGCGs) of the jaws. There have since been 4 additional published cases of NF1 patients with CGCGs of the jaws.

Clinical Cases: We report on 2 patients who presented with NF1 and aggressive CGCGs of the jaws. In both cases, the clinical course was characterized by numerous recurrences despite mechanical curettage and surgical resection.

Conclusions: We review proposed mechanisms to explain the apparent association between NF1 and an increased incidence of CGCGs of the jaws. While the presence of CGCGs of the jaws in patients with NF1 could represent a coincidental association or a true genetic linkage, we propose that this phenomenon is most likely related to NF1-mediated osseous dysplasia. Compared to normal bone, the Nf1-haploinsufficient bone in a patient with NF1 may be less able to remodel in response to as of yet unidentified stimuli (e.g. excessive mechanical stress and/or vascular fragility), and consequently may be more susceptible to developing CGCG-like lesions. Alternatively, the CGCG in NF1 patients could represent a true neoplasm, resulting from additional, as of yet unidentified, genetic alterations to Nf1haploinsufficient bone. 


\section{Introduction}

Neurofibromatosis 1 (NF1) is a relatively common (1:3,500 newborns $\left.{ }^{1}\right)$ autosomal dominantly inherited genetic disorder, caused by a spectrum of mutations affecting the neurofibromatosis 1 (Nf1) gene. The $N f 1$ gene is located at 17q11.2, spans more than 350 Kbs and comprises 60 exons. To date, more than 200 separate mutations have been identified. ${ }^{2}$ About $50 \%$ of NF1 cases occur in patients with unaffected parents and are believed to represent spontaneous mutations.

Mutations ${ }^{3}$ range from nonsense point mutations that introduce stop codons (30$40 \%)$, missense mutations that alter the amino acid sequence (5-10\%), microdeletions (5$10 \%)$, to intron mutations that affect splicing (20-35\%). Approximately $2-10 \%$ of cases are believed to be due to large $(1.5 \mathrm{Mb})$ gene deletions that also involve portions of neighboring non-Nf1 related coding sequences. With few exceptions, attempts to correlate phenotypical expression to genotype have been largely unsuccessful.

The heterogeneous nature of $N f 1$ mutations and the relatively high rate of new mutations makes molecular testing difficult. Linkage analysis, with the goal of identifying chromosomes that carry the Nf1 mutation, is generally effective for prenatal diagnosis. Direct mutational analysis is rarely performed outside of the research laboratory. In most cases, however, a diagnosis of NF1 can be reached based on clinical diagnostic criteria originally established by the 1987 National Institutes of Health Neurofibromatosis Consensus Development Conference (Table 1).

In addition to the diagnostic criteria listed in Table 1, affected patients are prone to developing a number of specific neoplastic and non-neoplastic conditions at an increased frequency. The most commonly encountered tumors in patients with NF1 include neurofibromas and optic gliomas. Malignant peripheral nerve sheath tumors develop from pre-existing plexiform neurofibromas in approximately $2-16 \%$ of patients ${ }^{4}$, and are the leading 
cause of death in NF1 patients. Pheochromocytomas and juvenile chronic myeloid leukemia are also seen with increased frequency. Examples of common non-neoplastic conditions include poorly-characterized high signal intensity lesions on T2-weighted Magnetic Resonance (MR) images of the brain known as "unidentified bright objects", learning disabilities, seizures, secondary hypertension and macrocephaly. Commonly seen soft tissue lesions in the oral cavity include neurofibromas and enlarged fungiform papillae. ${ }^{5}$

Skeletal findings include scoliosis-like spinal curvature, short stature, tibial pseudoarthrosis and dysplastic lesions of the skeleton. Certain osseous abnormalities, such as sphenoid dysplasia, are considered a diagnostic feature for NF1 (Table 1). Although not restricted to NF1, over $50 \%$ of patients with an osseous defect of the greater wing of the sphenoid bone have NF1. The nature of these hard tissue lesions is poorly defined, but can involve bones that develop by both intramembranous and endochondral ossification. These lesions are generally assumed to represent abnormal development of mesodermal elements and hence are considered primary osseous dysplasias. In some, but not all cases, an adjacent neurofibroma or other soft tissue lesion that is presumed to directly erode bone is implicated.

Skeletal lesions specific to the jaws include ${ }^{6}$ enlarged mandibular foramen and canals, branched mandibular canals, widening of the coronoid notch, deformity of the condylar head, lengthening of the condylar neck, irregularity of the inferior mandibular cortex, intrabony cyst-like lesions and thinning and lateral bowing of the ramus. Also noted on CT analysis is the presence of an increased amount of fat-like soft tissue immediately adjacent to the affected ramus.

We report 2 patients with NF1 who presented with aggressive central giant cell granulomas (CGCGs) of the jaws. In both cases, the clinical course was characterized by significant osseous destruction, poor response to treatment and numerous recurrences. 


\section{Case Presentation:}

\section{$\underline{\text { Case 1: }}$}

In 1996, a12 year-old boy presented with a large mass of the right palate. Intra-oral examination revealed significant palatal expansion (Figure 1). The lesion crossed the midline, and extended to both the soft palate and the buccal vestibule. The extent of maxillary destruction was evident on coronal (Figure 2a) and axial (Figure 2b) Computed Tomography (CT) scans.

The patient's past medical history was significant for Neurofibromatosis 1, diagnosed when the patient was 3 years old. Besides multiple café-au-lait macules, axillary freckling and bilateral Lisch nodules, the patient also had multiple neurofibromas, a number of which involved the spine. He was the only child of unaffected parents. The patient was taking fluoxetine hydrochloride and gabapentin secondary to chronic spinal pain. Incisional biopsy of the lesion revealed aggregates of multinucleated giant cells in a background of cellular fibrous connective tissue with foci of hemorrhage, consistent with CGCG (Figure 3). Serum parathyroid homone (PTH) and calcium were within normal limits. The patient was taken to the operating room and a right hemi-maxillectomy was performed. The surgical line of resection was extended to the left maxillary central incisor site. Histologic examination of the resected specimen was consistent with that of a CGCG.

The patient was lost to follow up until December 2002, at which time he presented with a recurrent palatal mass involving the remaining portion of the right maxilla, the left anterior alveolar process and anterior hard palate (Figure 4). CT imaging (Figure 5) demonstrated that the lesion extended to the left premolar region, the right infra-orbital rim, the right nasal septum and the pterygoid plate. Again, biopsy of the lesion was consistent with a recurrent central giant cell granuloma. The recurrent lesion was surgically excised via a left anterior completion hemi-maxillectomy. The surgical site extended laterally to the left 
maxillary canine region. In April of 2003, the maxillary defect (Figure 6) was reconstructed with a vascularized free fibular graft. During graft harvesting, a markedly enlarged peroneal nerve was noted (Figure 7). At one year follow-up, no evidence of recurrence was noted.

\section{Case 2:}

A 34 year old female presented with fullness of her right mandibular symphysis area. Her past medical history was significant for a CGCG of the anterior mandible that had been resected at10 years of age. Serum parathyroid hormone $(\mathrm{PTH})$ and calcium were within normal limits. At age 20, the patient underwent reconstructive surgery with autologous bone grafting and osseointegrated dental implants. During the procedure, a small osseous defect was noted in the surgical field, which on histological examination proved to be a recurrent CGCG. The lesion was treated by peripheral ostectomy. Five years later, the patient's son was diagnosed with NF1. Subsequent to this, the patient and her parents were sent to a Medical Geneticist for assessment. It was determined, based on clinical presentation, that both the patient and her father had NF1.

Radiographic examination (Figure 8) revealed numerous radiolucent lesions surrounding the mandibular implants, bilateral maxillary and right mandibular lesions. Intralesional injection of triamcinolone (according to the protocol established by Carlos and Sedano ${ }^{7}$ ) over an eight month period failed to result in any radiographically-evident improvement. The lesions were surgically debrided, and the patient was placed on an investigational bisphosphonate protocol.

\section{Discussion}

Central giant cell granuloma (CGCG) is a benign central lesion of bone, primarily involving the jaws, of variably aggressive nature characterized by ${ }^{8}$ aggregates of 
multinucleated giant cells in a background of cellular vascular fibrous connective tissue and spindle-shaped mononuclear stromal cells, often with extravasation of red blood cells.

Currently there are no reliable criteria for correlating clinical aggressiveness with histological presentation $^{9}$. Recurrences are not uncommon, with an estimated 5 year disease-free success rate of only $75 \%$ following conventional surgical therapy. ${ }^{10}$ The rate of recurrence is even more prominent among young males.

CGCG most likely represents a non-neoplastic reactive process. ${ }^{11}$ Proposed etiologies include intraosseous hemorrhage ${ }^{12}$, trauma ${ }^{13}$, faulty bone development and abnormal repair of bone. Arguing in favor of a reactive process is the occasional association of CGCGs with other pre-existing bone lesions, such as fibrous dysplasia, ${ }^{14}$ Pagets disease of bone ${ }^{15}$, central odontogenic fibroma ${ }^{16,17}$, traumatic bone cyst ${ }^{18}$ and ossifying fibroma ${ }^{19,20}$. However, the possibilities that some subtypes of CGCG of the jaws (e.g. those associated with syndromes) may represent a neoplastic process ${ }^{21,22}$, akin to the giant cell tumor of bone ${ }^{23,24}$ or have a systemic component, ${ }^{25}$ has not been conclusively ruled out.

In CGCGs, the multinucleated giant cells (MGCs) are often concentrated in areas of hemorrhage, adjacent to blood vessels. Although the MGCs seen in CGCG share some similarities with the osteoclast ${ }^{26,27}$, there are enough phenotypic differences to suggest that these may not be true osteoclasts ${ }^{28}$. It is generally accepted that these MGCs develop as a result of cell-cell fusion of mononuclear cells ${ }^{29}$. Possible origins of these mononuclear cells include endothelial cells ${ }^{30}$, myofibroblasts ${ }^{31}$, macrophages, or mononuclear hematopoietic progenitor cells of myeloid lineage. ${ }^{26}$

A number of conditions can present with lesions that histologically are indistinguishable from the central giant cell granuloma (CGCG) of bone, including brown tumors of hyperparathyroidism, cherubism, and, less commonly, a number of inherited syndromes. These include Ramon syndrome (gingival fibromatosis, hypertrichosis, epilepsy, mental and somatic retardation and cherubism-like lesions) ${ }^{32}$, Schimmelpenning syndrome ${ }^{33}$, 
Noonan syndrome ${ }^{34,35}$ (short stature, ocular hypertelorism, pulmonic stenosis, webbed neck), "Noonan-like syndrome, cherubism, and polyarticular pigmented villonodular synovitis" (additional findings of multiple lesions of pigmented villonodular synovitis affecting multiple weight-bearing bones) and "ocular-ectodermal syndrome" ${ }^{36}$.

Interestingly, NF1 demonstrates phenotypic overlap with Noonan syndrome in approximately $12 \%$ of patients and multiple giant cell lesions have been reported in patients with Noonan syndrome. ${ }^{34,35}$ Missense mutations in the gene PTPN11 ${ }^{37}$, which encodes the non-receptor tyrosine phosphatase protein SHP-2 ${ }^{38}$ and is responsible for Noonan syndrome, were identified in two siblings inheriting Noonan-like/ multiple giant cell lesions syndrome $e^{39}$ and in one patient who progressed from Noonan syndrome to multiple lentigines/LEOPARD syndrome and ultimately to Noonan-like/ multiple giant cell lesions syndrome. ${ }^{40}$ Moreover, there has been one report of a patient with NF1-Noonan-like phenotype with a solitary CGCG of the jaws. ${ }^{41}$ This NF1-Noonan-like phenotype is believed to represent 2 separate conditions. Watson syndrome, characterized by overlapping mild features of both NF1 and Noonan-like syndrome has been linked to the Nf1 gene. NF1Noonan syndrome, an entity of its own right, is believed to be the result of the independent segregation of a both classical NF1 phenotype and a Noonan syndrome phenotype. ${ }^{42}$ The observation that the genes responsible for these 2 conditions are located on separate chromosomes does not rule out the possibility of an as yet undefined interaction between neurofibromin and the Noonan syndrome gene product SHP-2. However, the basis for this apparent association between these 2 conditions and CGCGs of the jaws remains unclear.

$\mathrm{Kerl}^{43}$ first reported an association of NF1 with multiple CGCGs of the jaws. Excluding the patient with neurofibromatosis-Noonan syndrome ${ }^{41}$, there have been 4 additional reports of multiple CGCGs in patients with NF1. ${ }^{44,45,46,47}$ Molecular analysis of one of these cases ${ }^{47}$ uncovered a novel Nf1 splice mutation in the proband, resulting in the deletion of 53 amino acids within the GTPase-activating domain of neurofibromin. Additional cases of a giant cell tumor of 
the occipital bone ${ }^{48}$ and a patient with multiple "peripheral" giant cell granulomas ${ }^{49}$ associated with extensive resorption of the underlying bone have also been reported.

The apparent association between NF1 and an increased incidence of CGCGs of the jaws could represent a coincidental association, a genetic linkage or an underlying susceptibility to developing CGCG-like lesions in qualitatively abnormal bone.

Arguing against a coincidental association is the relative rarity of CGCG. A Dutch study $^{50}$ reviewing all histologically confirmed cases of CGCG of the jaws in Holland over a five year period reported an incidence of $0.00011 \%$. Of 83 cases of CGCG identified, 2 patients had NF1 and 1 patient had NF1 with a Noonan-like phenotype. This represents at least $3.6 \%$ of all cases of CGCGs, a 100 -fold increase over the estimated prevalence of NF1 $\left(0.029 \%\right.$ of the population $\left.{ }^{2}\right)$. Moreover, multiple CGCGs are very rare in the absence of hyperparathyroidism or cherubism.

Alternatively, the association between NF1 and CGCG could represent a true genetic linkage; resulting from defects or deletions of two or more genes that map near each other on the same region of a chromosome. Arguing against a genetic linkage is the lack of direct evidence of a specific genetic basis for CGCG.

We believe that the increased incidence of CGCGs of the jaws in patients with NF1 most likely represents an inherent susceptibility to intraosseous trauma and/or hemorrhage in bone previously altered by an underlying osseous dysplasia. This qualitatively abnormal bone would be more susceptible to developing CGCG-like lesions in response to as of yet unidentified factors such as excessive mechanical stress and/or vascular fragility. In addition to sphenoid dysplasia, patients with NF1 have an increased incidence of additional skeletal dysplasias including scoliosis, thinning and/or bowing of the weight bearing long bones, pseudoarthrosis, and ill-defined fibrocystic lesions of bone ${ }^{51}$.

Although little is known about the underlying basis for the development of dysplastic bone in $\mathrm{NF}^{52}$, several possible mechanisms have been proposed. These include a direct pressure 
effect from adjacent excessive soft tissue on developing and/or remodeling bone, altered function of the Nf1 gene product (neurofibromin), or loss of function of other genes coded for either within or contiguous to the deleted portion of the Nf1 gene.

Traditionally, the presence of altered bone in NF1 has been attributed to a direct pressure effect of excessive soft tissue, presumably from an adjacent neurofibroma, on developing and/or remodeling bone. However, this fails to account for the significant number of cases in which adjacent neurofibromas cannot be demonstrated. For example, histological analysis of a large number of biopsies from patients with tibial pseudoarthrosis ${ }^{53}$, which is seen in $1-4 \%$ in children with NF1, revealed the presence of neurofibroma-like tissue in only $40 \%$ of cases. In $45 \%$ of cases, a highly cellular non-specific fibrovascular tissue devoid of neural/Schwannian elements is noted.

The role of the Nf1 gene in skeletal development has not been well characterized, although the demonstration of Nf1 mRNA expression and its protein product, neurofibromin, in both osteoblasts and osteoclasts suggests that it may play a role in both osteogenesis and bone homeostasis ${ }^{54}$. Specifically, the $N f 1$ gene codes for the neurofibromin protein, a putative tumor suppressor protein with GTPase-activating function that appears to be involved in the down regulation of ras signal transduction ${ }^{55}$. Ras activation plays an important role in cellular proliferation and differentiation. Nf1 mutations would therefore be expected to result in increased ras signal transduction. In support of this, it has been demonstrated ${ }^{54}$ that mice embryos heterozygous for $N f 1$ have higher levels of a number of specific downstream products of ras activation (phosphorylated p42 and p44 MAP kinases).

Yu et al ${ }^{56}$ recently demonstrated that $N f 1+/$ - (haploinsufficient) mice had normal bone mass but a tendency to decreased bone homeostasis compared to wild type. Specifically, loss of one Nf1 allele was associated with deregulated Ras signaling in bone marrow osteoprogenitor cells, decreased osteoblastic induction potential and premature apoptosis of osteoblasts. However, Nf1 haploinsuffiency alone was not sufficient to cause bone lesions, 
suggesting that other events (e.g. loss of the remaining Nf1 allele, loss of an additional gene or an adverse change in the microenvironment) are required prior to the development of pathologic changes in the bone.

Abdel-Wanis and Kawahara ${ }^{57}$ have proposed several mechanisms by which decreased neurofibromin function could result in altered bone formation. Under normal conditions, ras activation negatively regulates type I collagen synthesis ${ }^{58}$, the major organic constituent of bone. In Nf1 mutations, increased ras activity would be expected to result in a decrease in type I collagen gene expression. The resultant collagen-deficient bone would have a decreased ability to respond to functional demands, and hence would be more prone to developing intraosseous defects. In addition, a predisposition to developing increased amounts of architecturally abnormal granulation tissue has been demonstrated in experimentally-induced skin wounds in mice heterozygous for the $\mathrm{Nf1}$ gene $(\mathrm{Nf1+}+-){ }^{59}$ Theoretically, a similar osteoblastic response to trauma could lead to an abnormal reparative process within bone characterized by the deposition of atypical fibrous connective tissue. A third explanation may be related to the identification of three genes, normally transcribed from the opposite strand of Nf1, within one of the Nf1 introns. These are: OMgp (oligodendrocytemyelin glycoprotein), EVI2B (ecotropic viral insertion site 2 protein $B$ ) and EVI2A (ecotropic viral insertion site 2 protein A). While the exact role of these 3 proteins is poorly characterized, OMgp appears to block activation of the $c$-fos proto-oncogene via alteration of platelet-derived growth factor function ${ }^{60}$. Increased levels of $c$-fos mRNA have been identified in the bone lesions of patients with fibrous dysplasia ${ }^{61}$. Therefore, it is possible that in cases of NF1 in which the deletion includes the gene for OMgp, the resultant increased levels of $c$ fos could predispose to the development of a fibrous dysplasia-like bone.

The observation that $N f 1$ haploinsuffiency alone is not sufficient to cause bone lesions ${ }^{56}$ implies that other events (e.g. loss of the remaining Nf1 allele, loss of an additional 
gene or an adverse change in the microenvironment) are required prior to the development of CGCG-like lesions in the bone.

\section{Conclusion}

We report 2 patients with NF1 who presented with central giant cell granulomas (CGCGs) of the jaws. In both cases, the clinical course was characterized by significant osseous destruction and recurrence.

While the presence of CGCGs of the jaws in patients with NF1 could represent a coincidental association or a genetic linkage, we propose that this phenomenon is most likely related to NF1-mediated osseous dysplasia. Compared to normal bone, the Nf1haploinsufficient bone in a patient with neurofibromatosis 1 may be less able to remodel in response to as of yet unidentified stimuli (e.g. excessive mechanical stress and/or vascular fragility), and consequently may be more susceptible to developing CGCG-like lesions. Alternatively, the CGCG in NF1 patients could represent a true neoplasm, resulting from additional, as of yet unidentified, genetic alterations to Nf1-haploinsufficient bone. 
Figure 1: Case 1. Clinical photograph of 12 year old male at initial presentation. There is a large expansile mass of the right palate, which crosses the midline.

Figure 2a: Case 1. Coronal CT scan of patient at initial presentation demonstrates large lesion expanding the right maxilla. The lesion occupies the entire maxillary antrum and extends into the nasal fossa.

Figure 2b: Case 1. Axial CT scan of patient at initial presentation demonstrates large lesion expanding the right maxilla. The outer cortical plate of bone is focally destroyed.

Figure 3: Case 1. Histologic examination of tissue removed at incisional biopsy revealed aggregates of multinucleated giant cells in a cellular fibrous connective tissue background. Also noted are foci of hemorrhage. Hematoxylin and eosin stain. Initial magnification 40x.

Figure 4: Case 1. Clinical photograph of patient at follow-up (age 18). There is a recurrent palatal mass involving both the remaining portion of the right maxilla, the left anterior maxilla and the anterior hard palate.

Figure 5: Case 1: Coronal CT scan of patient at follow up. A recurrent multilocular lesion is evident involving the right maxillary antrum and nasal fossa.

Figure 6: Case 1: The extent of bone destruction is evident on this post-operative 3Dimensional CT reconstruction. 
Figure 7: Case 1. During graft harvesting to reconstruct maxilla with a vascularized free fibular graft, a markedly enlarged peroneal nerve was noted.

Figure 8: Case 2: Panoramic radiograph of 34 year old female who presented with fullness of her right mandibular symphysis area. Numerous radiolucent lesions involving the anterior and right posterior mandible and the bilateral maxilla are noted. 


\section{Table 1: Diagnostic Criteria for Neurofibromatosis 1}

(1987 National Institutes of Health Consensus Development Conference ${ }^{62}$ )

The diagnostic criteria for NF-1 are met in an individual if two or more of the following are found:

- Six or more café-au-lait macules over $5 \mathrm{~mm}$ in greatest diameter in prepubertal individuals and over $15 \mathrm{~mm}$ in greatest diameter in postpubertal individuals.

- Two or more neurofibromas of any type or one plexiform neurofibroma.

- Freckling in the axillary or inguinal region.

- Optic glioma.

- Two or more Lisch nodules (iris hamartomas).

- A distinctive osseous lesion such as sphenoid dysplasia or thinning of long bone cortex with or without pseudarthrosis.

- A first-degree relative (parent, sibling, or offspring) with NF-1 by the above criteria.

Note: Although not part of the NIH Consensus Development Conference recommendations, it has been recommended that infants with multiple café-au-lait macules should be reassessed annually until age 10 years for the development of additional diagnostic criteria ${ }^{63}$. 


\section{REFERENCES}

${ }^{1}$ Carroll SL, Stonecypher MS. Tumor suppressor mutations and growth factor signaling in the pathogenesis of NF1-associated nerve sheath tumors. 1. The role of tumor suppressor mutations. J Neuropath Exper Biol 2004;63:1115-23.

${ }^{2}$ Rasmussen SA, Friedman JM. Nf1 gene and neurofibromatosis. Am J Epidemiol 2000;151:33-40.

${ }^{3}$ Thomson SA, Fishbein L, Wallace MR. Nf1 mutations and molecular testing. J Child Neurol 2002;17:555-61.

${ }^{4}$ Reynolds RM, Browning GG, Nawroz I, Campbell IW. Von Recklinghausen's neurofibromatosis: neurofibromatosis type 1. Lancet 2003;361:1552-4.

${ }^{5}$ Shapiro SD, Abramovitch K, Van Dis ML, Skoczlas LJ, Langlais RP, Jorgenson RJ, et al. neurofibromatosis: oral and radiographic manifestations. Oral Surg Oral Med Oral Pathol $1984 ; 58: 493-8$.

${ }^{6}$ Lee L, Yan YH, Pharoah MJ. Radiographic features of the mandible in neurofibromatosis: a report of 10 cases and review of the literature. Oral Surg Oral Med Oral Pathol Oral Radiol Endod 1996; 81:361-7.

${ }^{7}$ Carlos R, Sedano HO. Intralesional corticosteroids as an alternative treatment for central giant cell granuloma. Oral Surg Oral Med Oral Pathol Oral Radiol Endod 2002;93:161-6.

${ }^{8}$ Jaffe HL. Giant cell reparative granuloma, traumatic bone cyst and fibrous (fibro-osseous) dysplasia of the jawbones. Oral Surg Oral Med Oral Pathol 1953;6:159-75.

${ }^{9}$ Chuong R, Kaban LB, Kozakewich H, Perez-Atayde A. Central giant cell lesions of the jaws: a clinicopathologic study. J Oral Maxillofac Surg 1986;44:708-13.

${ }^{10}$ De Lange J, van den Akker HP, Klip H. Incidence and disease-free survival after surgical therapy of central giant cell granulomas of the jaws in the Netherlands: 1990-1995. Head Neck 2004;26:792-5. 
11 Sciubba JJ, Fantasia JE, Kahn LB. Nonodontogenic lesions. In: Atlas of Tumor Pathology: Tumors and Cysts of the Jaw. Armed Forces Institute of Pathology. Washington, D.C. $2001 ; 161-70$.

${ }^{12}$ Dorfman HD, Czerniak B. Giant cell lesions. In: Dorfman HD, Czerniak B, editors. Bone tumors. St Louis: Mosby, Inc; 1995;559-606.

${ }^{13}$ El-Labban NG. Intravascular fibrin thrombi and endothelial cell damage in central giant cell granuloma. J Oral Pathol Med 1997;26:1--5.

${ }^{14}$ Lustmann J, Soskolne WA, Lewin-Epstein J. Central giant cell granuloma and periapical fibrous dysplasia occurring in the same jaw. Int J Oral Surg 1978;7:11-5.

${ }^{15}$ Upchurch KS, Simon LS, Schiller AL, Rosenthal DI, Campion EW, Krane SM. Giant cell reparative granuloma of Paget's disease of bone: a unique clinical entity. Ann Intern Med 1983;98:35-40.

${ }^{16}$ Odell EW, Lombardi T, Barrett AW, Morgan PR, Speight PM. Hybrid central giant cell granuloma and central odontogenic fibroma-like lesions of the jaws. Histopathol 1997;30:165-71.

${ }^{17}$ Allen CM, Hammond HL, Stimson PG. Central odontogenic fibroma, WHO type. A report of three cases with an unusual associated giant cell reaction. Oral Surg Oral Med Oral Pathol 1992;73:62-6.

${ }^{18}$ Chiba I, The BG, lizuka T, Fukuda H. Conversion of a traumatic bone cyst into central giant cell granuloma: implications for pathogenesis. A case report. J Oral Maxillofac Surg 2002; $60: 222-5$

${ }^{19}$ Penfold CN, McCullagh P, Eveson JW, Ramsay A. Giant cell lesions complicating fibro-osseous conditions of the jaws. Int J Oral Maxillofac Surg1993;22:158-62. 
${ }^{20}$ Kaffe I, Ardekian L, Taicher S, Littner MM, Buchner A. Radiologic features of central giant cell granuloma of the jaws. Oral Surg Oral Med Oral Path Oral Radiol Endod 1996;81:720-6.

${ }^{21}$ Carinci F, Piattelli A, Martinelli M, Palmieri A, Rubini C, Fioroni M, et al. Genetic profiling of central giant cell granulomas of the jaws. J Craniofac Surg 2005;16:399-407.

${ }^{22}$ Buresh CJ, Seemayer TA, Nelson M, Neff JR, Dorfman HD, Bridge J. t(X;4)(q22;q31.3) in giant cell reparative granuloma. Cancer Genet Cytogenet 1999;115:80-1.

${ }^{23}$ Strauss LG, Dimitrakopoulou-Strauss A, Koczan D, Bernd L, Haberkorn U, Ewerbeck V, et al. ${ }^{18}$ F-FDG kinetics and gene expression in giant cell tumors. J Nucl Med 2004;45:152835.

${ }^{24}$ Kauzman A, Li SQ, Bradley G, Bell RS, Wunder JS, Kandel R. Central giant cell granuloma of the jaws: assessment of cell cycle proteins. J Oral Pathol Med 2004;33:170-6.

${ }^{25}$ De Souza PE, Gomez RS, Xavier GM, dos Santos JS, Gollob KL, Dutra WO. Systemic leukocyte activation in patients with central giant cell lesions. J Oral Pathol Med 2005;34:312-7.

${ }^{26}$ Liu B, Yu SF, Li TJ. Mulinucleated giant cells in various forms of giant cell containing lesions of the jaws express features of osteoclasts. J Oral Pathol Med 2003;32:367-75.

${ }^{27}$ Itonaga I, Hussein I, Kudo O, Sabokbar A, Watt-Smith S, Ferguson D, et al. Cellular mechanisms of osteoclast formation and lacunar resorption in giant cell granuloma of the jaw. J Oral Pathol Med 2003;32:224-31.

${ }^{28}$ Tobon-Arroyave SI, Franco-Gonzalez LM, Isaza-Guzman DM, Florez-Moreno GA, BravoVasquez T, Castaneda-Pelaez DA, et al. Immunohistochemical expression of RANK, GR-alpha and CTR in central giant cell granulomas of the jaws. Oral Oncol 2005;41:4808. 
${ }^{29}$ Abe E, Mocharla H, Yamate T, Taguchi Y, Manolagas SC. Meltrin-alpha, a fusion protein involved in multinucleated giant cell and osteoclast formation. Calcif Tissue Int 1999;64:508-15.

${ }^{30}$ Adkins KF, Martinez MG, Robinson LH. Cellular morphology and relationships in giant cell lesions of the jaws. Oral Surg Oral Med Oral Pathol 1969;28:216-22.

${ }^{31}$ El-Labban NG, Lee KW. Myofibroblasts in central giant cell granuloma of the jaws: an ultrastructural study. Histopathol 1983;7:907-18.

32 Pino-Neto JM, Moreno AF, Silva LR, Velludo MA, Petan EB, Ribiero MV, et al. Cherubism, gingival fibromatosis, epilepsy, and mental deficiency (Ramon syndrome) plus juvenile rheumatoid arthritis. Am J Med Gen 1986;25:433-42.

${ }^{33}$ Ernst L, Quinn PD, Alawi F. Newly recognized oral manifestations of Schimmelpenning syndrome. Oral Surg Oral Pathol Oral Med Oral Radiol Endodon. 2005;100:186.

${ }^{34}$ Cohen MM Jr, Gorlin RJ. Noonan-like/multiple giant cell lesion syndrome. Am J Med Gen 1991;40:159-66.

${ }^{35}$ Edwards PC, Fox J, Fantasia JE, Goldberg J, Kelsch RD. Bilateral central giant cell granulomas of the mandible in an eight year-old girl with Noonan syndrome (Noonanlike/multiple giant cell lesions syndrome). Oral Surg Oral Pathol Oral Med Oral Radiol Endodon. 2005;99:334-40.

${ }^{36}$ Toriello HV, Bultman R, Panek RW, Hammers Y, Kohut G, Droste P, et al. Non-ossifying fibromas and giant cell reparative granulomas in a child with ocular-ectodermal syndrome. Clin Dysmorphol 1999;8:265-8.

${ }^{37}$ Tartaglia M, Mehler EL, Goldberg R, Zampino G, Brunner HG, Kremer H, et al. Mutations in PTPN11, encoding the protein tyrosine phospatase SHP-2, cause Noonan syndrome. Nat Genet 2001;29:465-8. 
${ }^{38}$ Chen B, et al. Mice mutant for Egfr and Shp2 have defective cardiac semilunar valvulogenesis. Nat Genet 2000;24:296-9.

${ }^{39}$ Tartaglia M, Kalidas K, Shaw A, Song X, Musat D, van der Burgt I, et al. PTPN11 mutations in Noonan syndrome: Molecular spectrum, genotype-phenotype correlation, and phenotypic heterogeneity. Am J Hum Genet 2002;70:1555-63.

${ }^{40}$ Sarkozy A, Obregon MG, Conti E, Esposito G, Mingarelli R, Pizzuti A, et al. A novel PTPN11 gene mutation bridges Noonan syndrome, multiple lentigines/LEOPARD syndrome and Noonan-like/multiple giant cell lesion syndrome. Eur J Hum Genet $2004 ; 12: 1069-72$.

${ }^{41}$ Yazdizadeh M, Tapia JL, Baharvand M, Radfar L. A case of neurofibromatosis-Noonan syndrome with a central giant cell granuloma. Oral Surg Oral Med Oral Path Oral Radiol Endod 2005;98:316-20.

${ }^{42}$ Bahuau M, Houdayer C, Assouline B, Blanchet-Bardon C, LeMerrer M, Lyonnet S, et al. Novel recurrent nonsense mutation causing neurofibromatosis type 1 (NF1) in a family segregating both NF1 and Noonan syndrome. Am J Med Genet 1998;75:265-72.

${ }^{43}$ Kerl H, Schroll K. \{Multiple giant cell granulomas of the jaws associated with Recklinghausen's neurofibromatosis\}. Wien Klin Wochenschr 1971;83:938-41.

${ }^{44}$ Van Damme PA, Mooren RE. Differentiation of multiple giant cell lesions, Noonan-like syndrome, and (occult) hyperparathyroidism: case report and review of the literature. Int $J$ Oral Maxillofac Surg 1994;23:32-6.

45 Ruggieri M, Pavone V, Polizzi A, Albanase S, Magro G, Merino M, et al. Unusual form of recurrent giant cell granuloma of the mandible and lower extremities in a patient with neurofibromatosis type 1. Oral Surg Oral Med Oral Path Oral Radiol Endod 1999;87:6772. 
${ }^{46}$ Ardekian L, Manor R, Peled M, Laufer D. Bilateral central giant cell granulomas in a patient with neurofibromatosis: report of a case and review of the literature. J Oral Maxillofac Surg 1999;57:869-72.

${ }^{47}$ Krammer U, Wimmer K, Wiesbauer P, Rasse M, Lang S, Mullner-Eidenbock A, Frisch H. Neurofibromatosis 1: a novel Nf1 mutation in an 11-year-old girl with a giant cell granuloma. J Child Neurol 2003;18:371-3.

${ }^{48}$ Opitz H, Petersen D, Heiss E, Duffner F, Meyermann R. Giant cell tumor of the occipital bone in a case of von Recklinghausen neurofibromatosis. Clin Neuropathol 1996;15:22630.

49 Junqyera LM, Lupi E, Lombardia E, Fresno MF. Multiple and synchronous peripheral giant cell granulomas of the gums. Ann Otol Rhinol Laryngol 2002;111:751-3.

${ }^{50}$ De Lange J, van den Akker HP. Clinical and radiological features of central giant cell lesions of the jaw. Oral Surg Oral Med Oral Path Oral Radiol Endod 2005; 99:464-70.

${ }^{51}$ Ruggieri M, Pavone C, DeLuca D, Franzo A, Tine A, Pavone L. Congenital bone malformations in patients with neurofibromatosis type 1. J Ped Orthoped 1999;19:301-5.

${ }^{52}$ Alwan S, Tredwell SJ, Friedman JM. Is osseous dysplasia a primary feature of neurofibromatosis 1 (NF1)? Clin Genet 2005;67:378-90.

${ }^{53}$ Hefti F, Bollini G, Dungl P, Fixsen J, Grill F, Ippolito E, et al. Congenital pseudoarthrosis of the tibia: history, etiology, classification and epidemiologic data. J Pediatr Orthop B 2000;9:11-5.

${ }^{54}$ Kuorilehto T, Nissinen M, Koivunen J, Benson MD, Peltonen J. NF1 tumor suppressor protein and mRNA in skeletal tissues of developing and adult normal mouse and NF1deficient embryos. J Bone Miner Res 2004;19:983-9.

${ }^{55}$ Viskochil D. Genetics of neurofibromatosis 1 and the Nf1 gene. J Child Neurol 2002;17:562-70. 
${ }^{56}$ YuX, Chen OL, Potter SM, Murthy SM, Li J, Pulcini JM, et al. Neurofibromin and its inactivation of Ras are prerequisites for osteoblast functioning. Bone 2005;36:793-802.

${ }^{57}$ Abdel-Wanis ME, Kawahara N. Bone development in neurofibromatosis I. Med Hypotheses 2003;60:459-62.

${ }^{58}$ Slack JL, Parker MI, Robinson VR, Bornstein P. Regulation of collagen I gene expression by ras. Mol Cell Biol 1992;12:4714-23.

${ }^{59}$ Atit RP, Crowe MJ, Greenhalgh DG, Wenstrup RJ, Ratner N. The Nf1 tumor suppressor regulates mouse skin wound healing, fibroblast proliferation, and collagen deposited by fibroblasts. J Invest Dermatol 1999;112:835-42.

${ }^{60}$ Habib AA, Gulcher JR, Hognason T, Zheng L, Stefansson K. The OMgp gene, a second growth suppressor within the Nf1 gene. Oncogene 1998;16:1525-31.

${ }^{61}$ Candeliere GA, Glorieux FH, Prud'homme J, St.-Arnaud R. Increased expression of the cfos proto-oncogene in bone from patients with fibrous dysplasia. NIEJM 1995;332:154651.

${ }^{62}$ Neurofibromatosis. NIH Consens Statement 1987;6:1-19.

${ }^{63}$ Gutman DH, Aylsworth A, Carey J, Korf B, Marks J, Pyeritz RE, et al. The diagnostic evaluation and multidisciplinary management of neurofibromatosis 1 and neurofibromatosis 2. JAMA 1997;278:51-7. 
Click here to download high resolution image

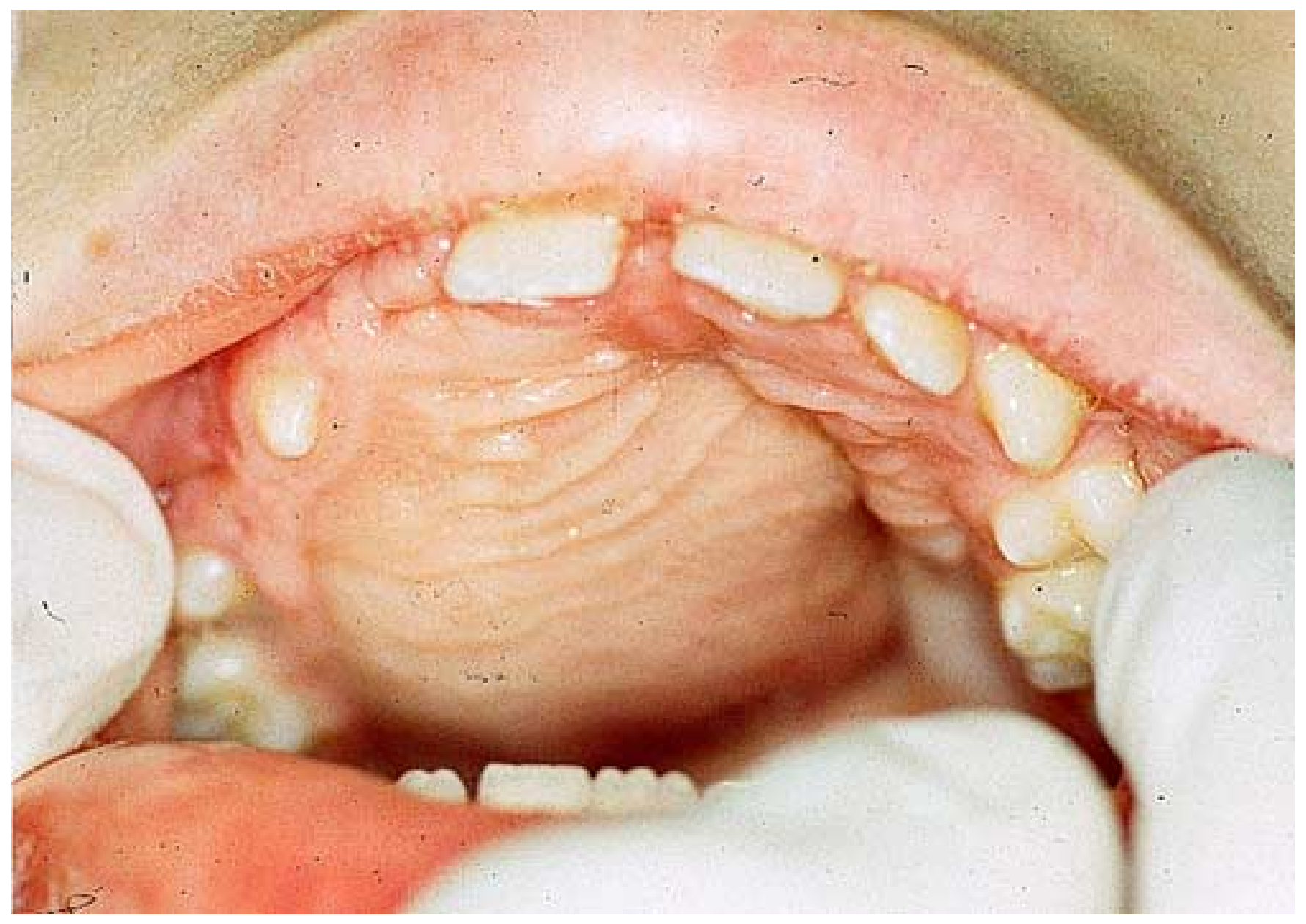


Figure $2 \mathrm{a}$
Click here to download high resolution image

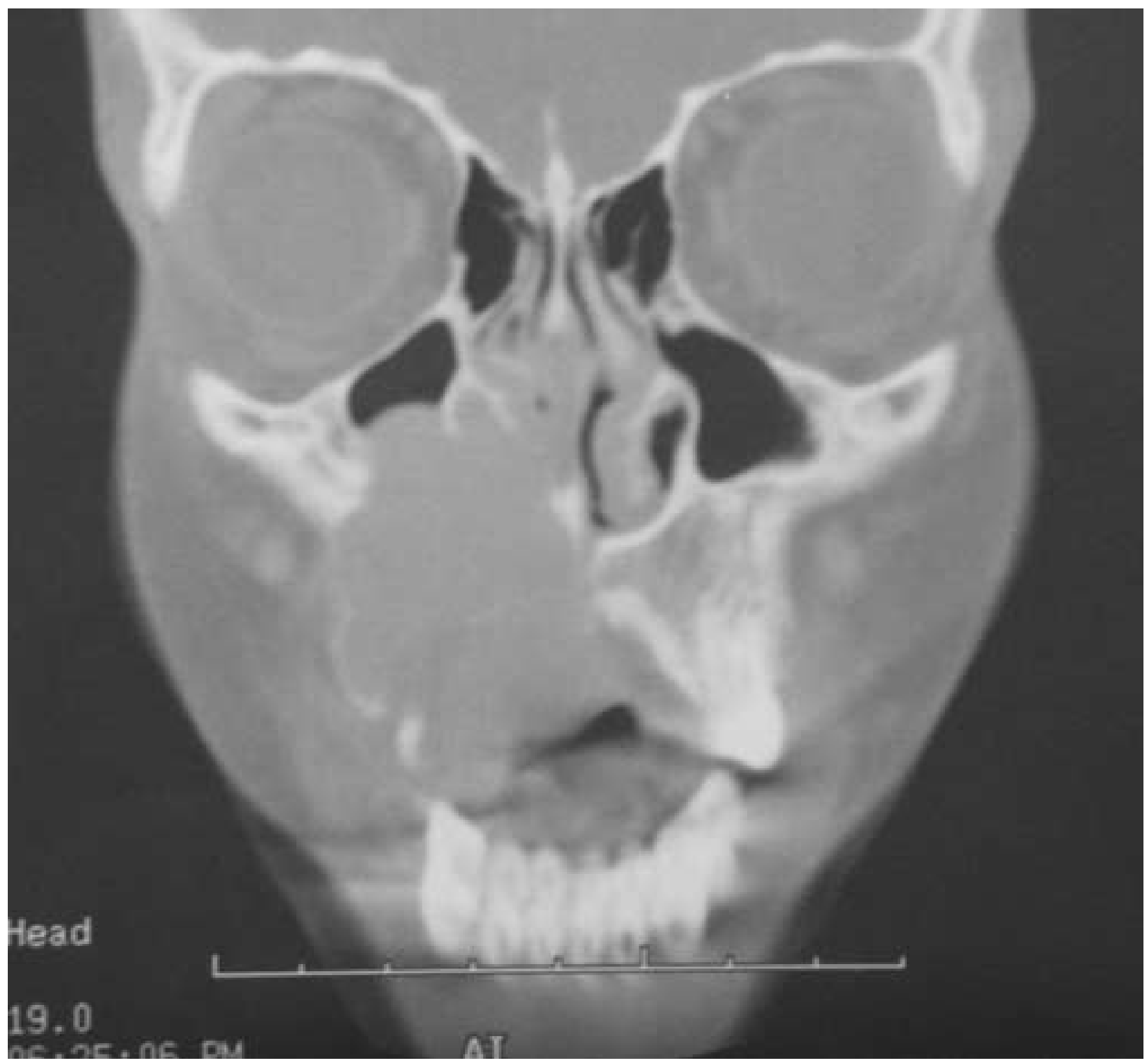


Figure $2 \mathrm{~b}$
Click here to download high resolution image

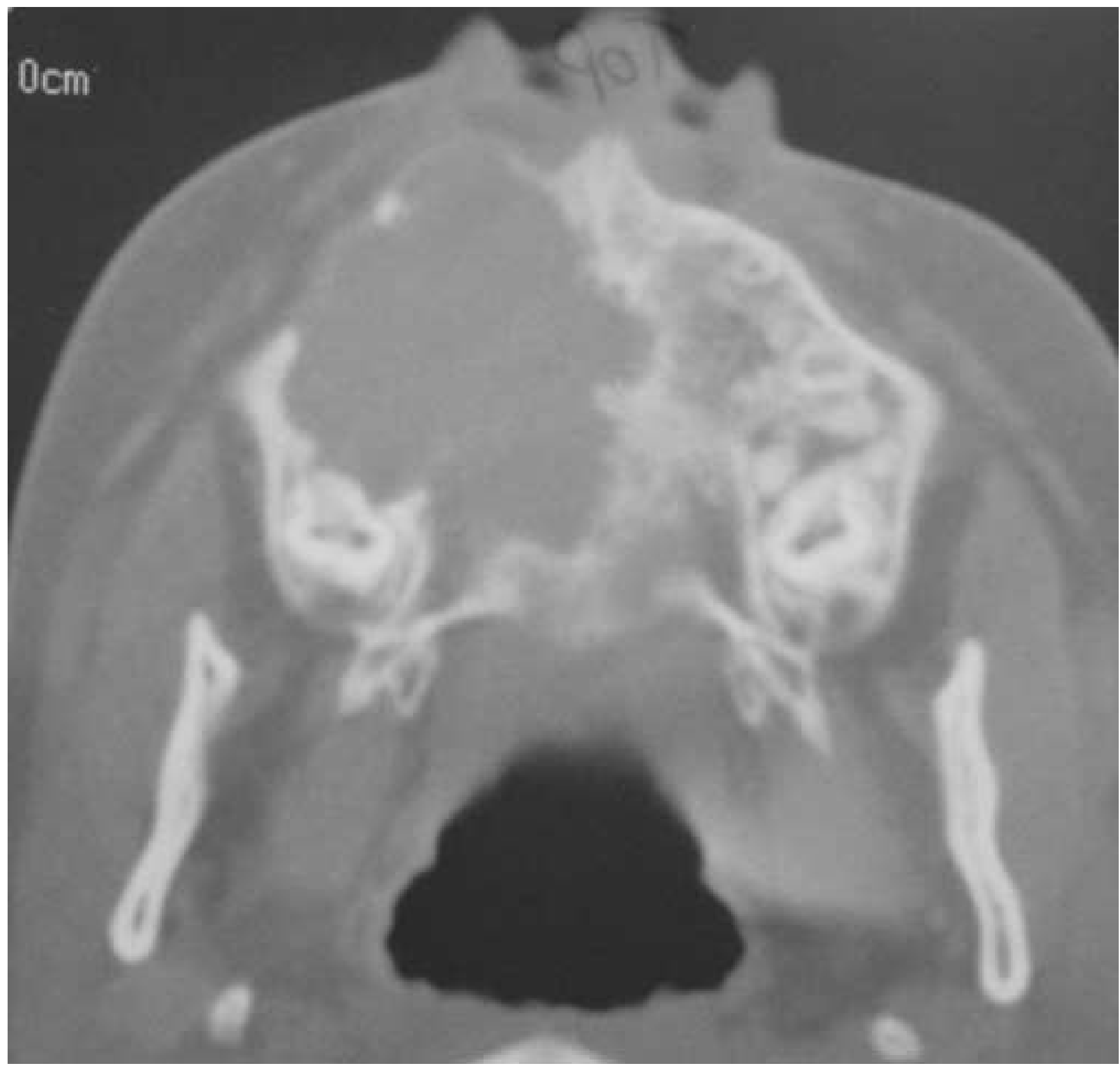


Click here to download high resolution image

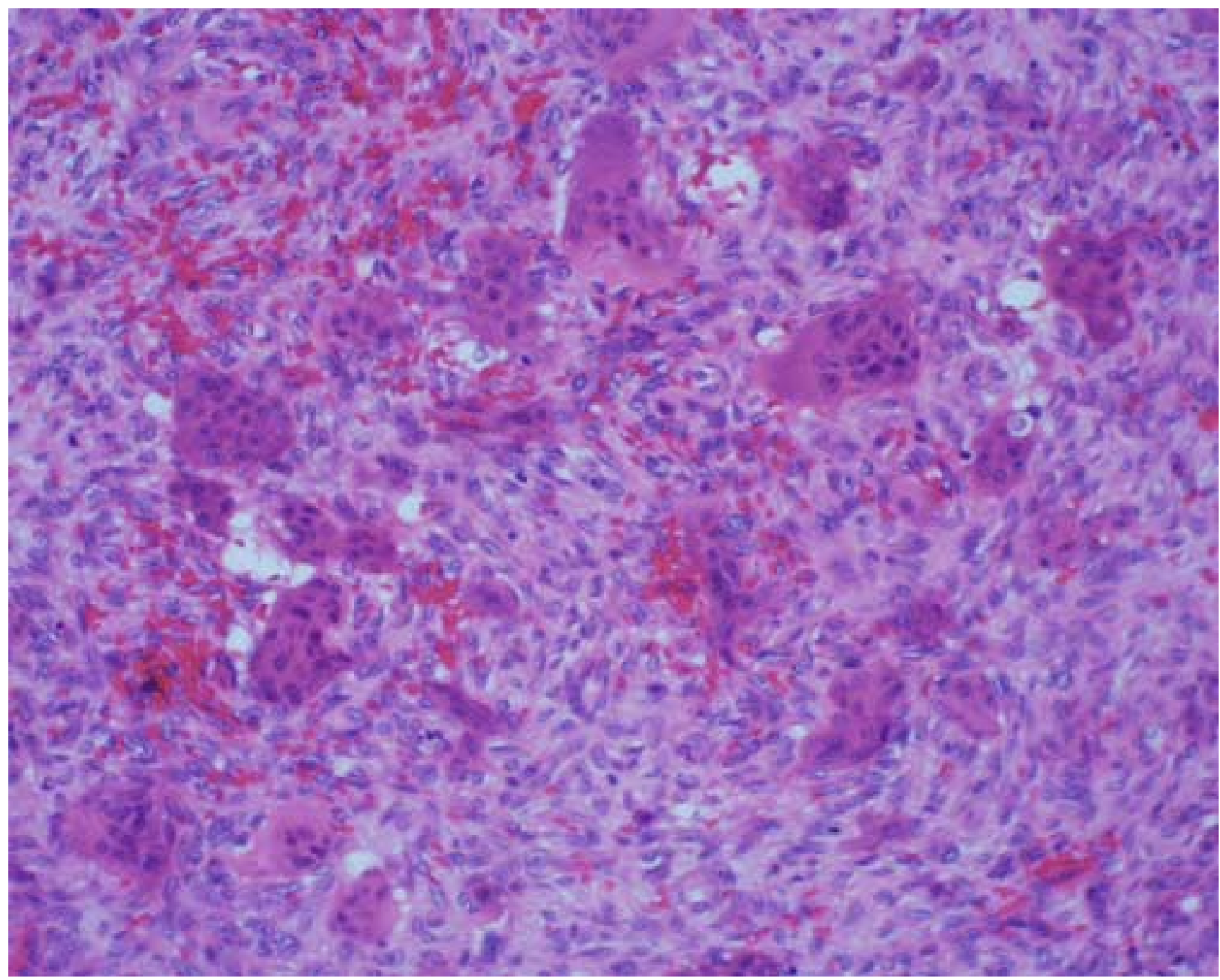


Figure 4
Click here to download high resolution image

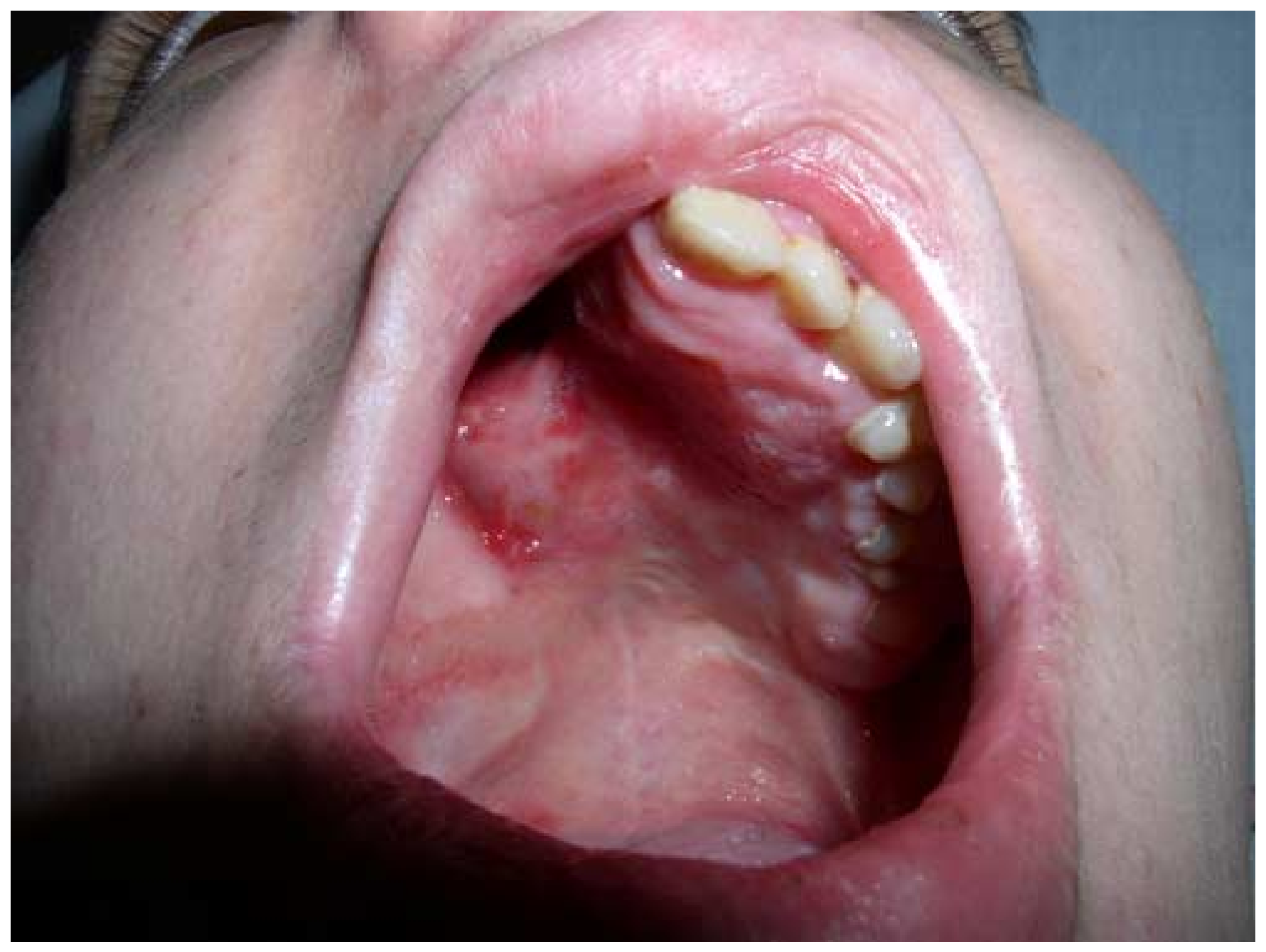


Click here to download high resolution image

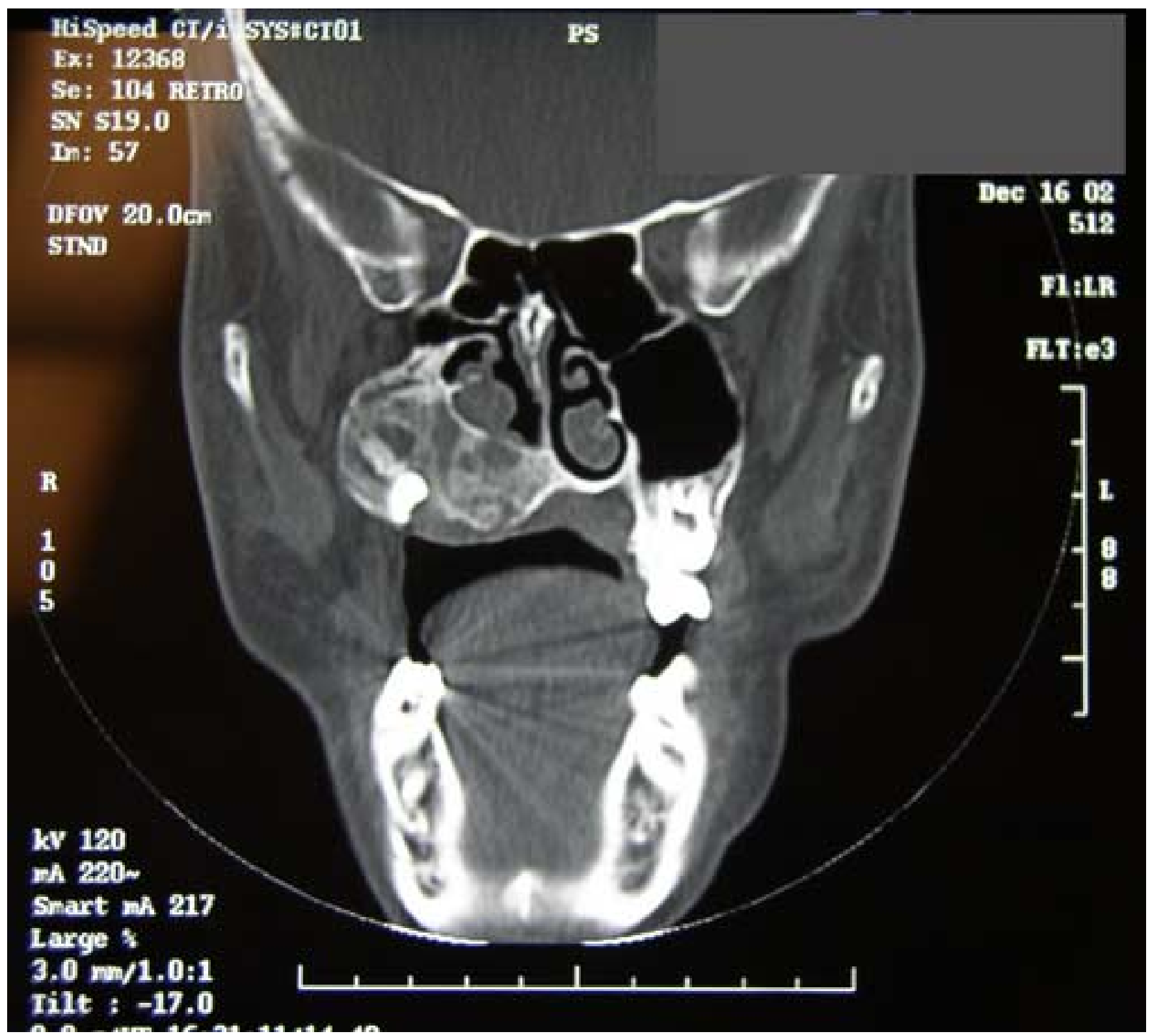


Figure 6
Click here to download high resolution image

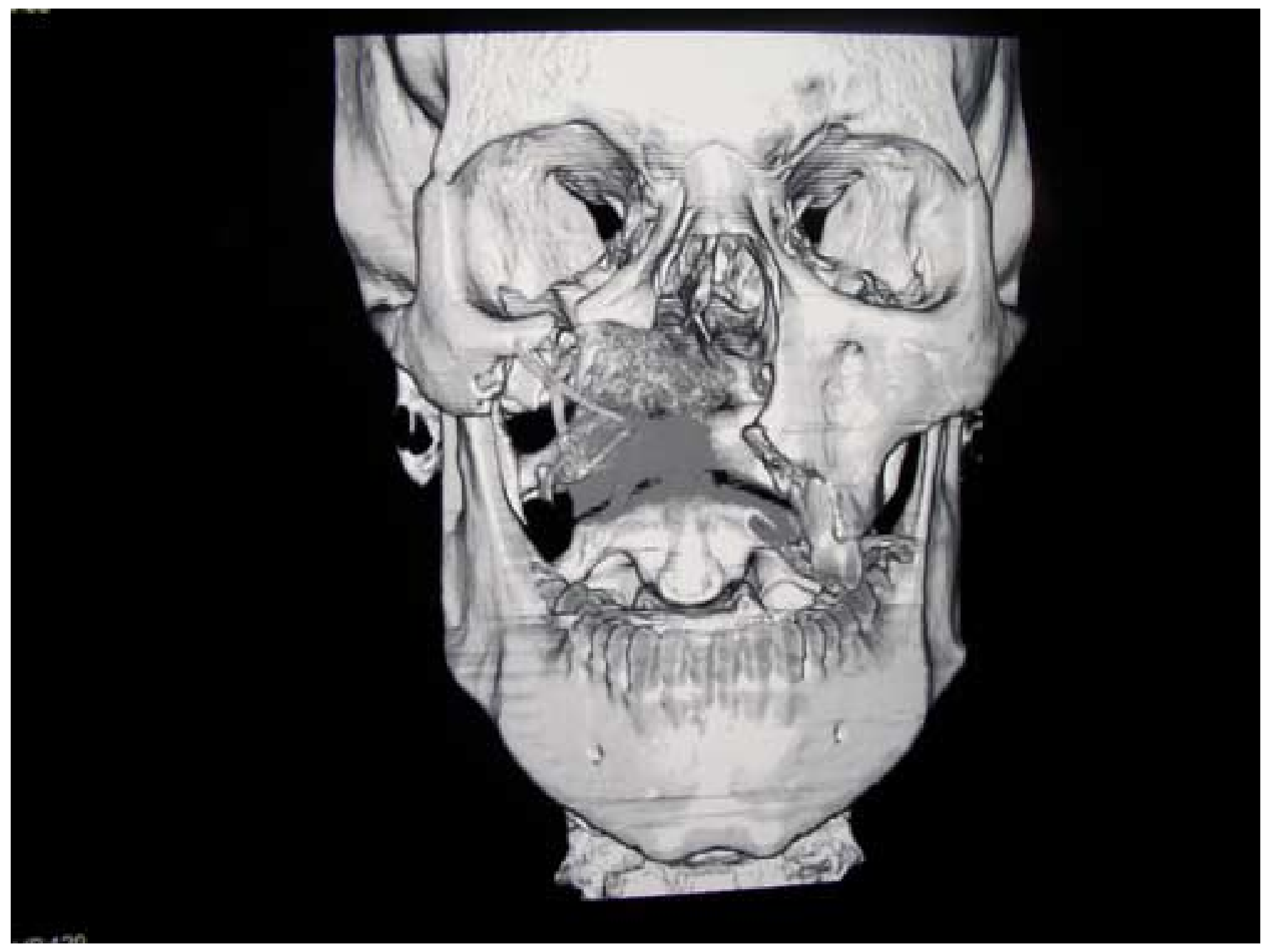


Click here to download high resolution image

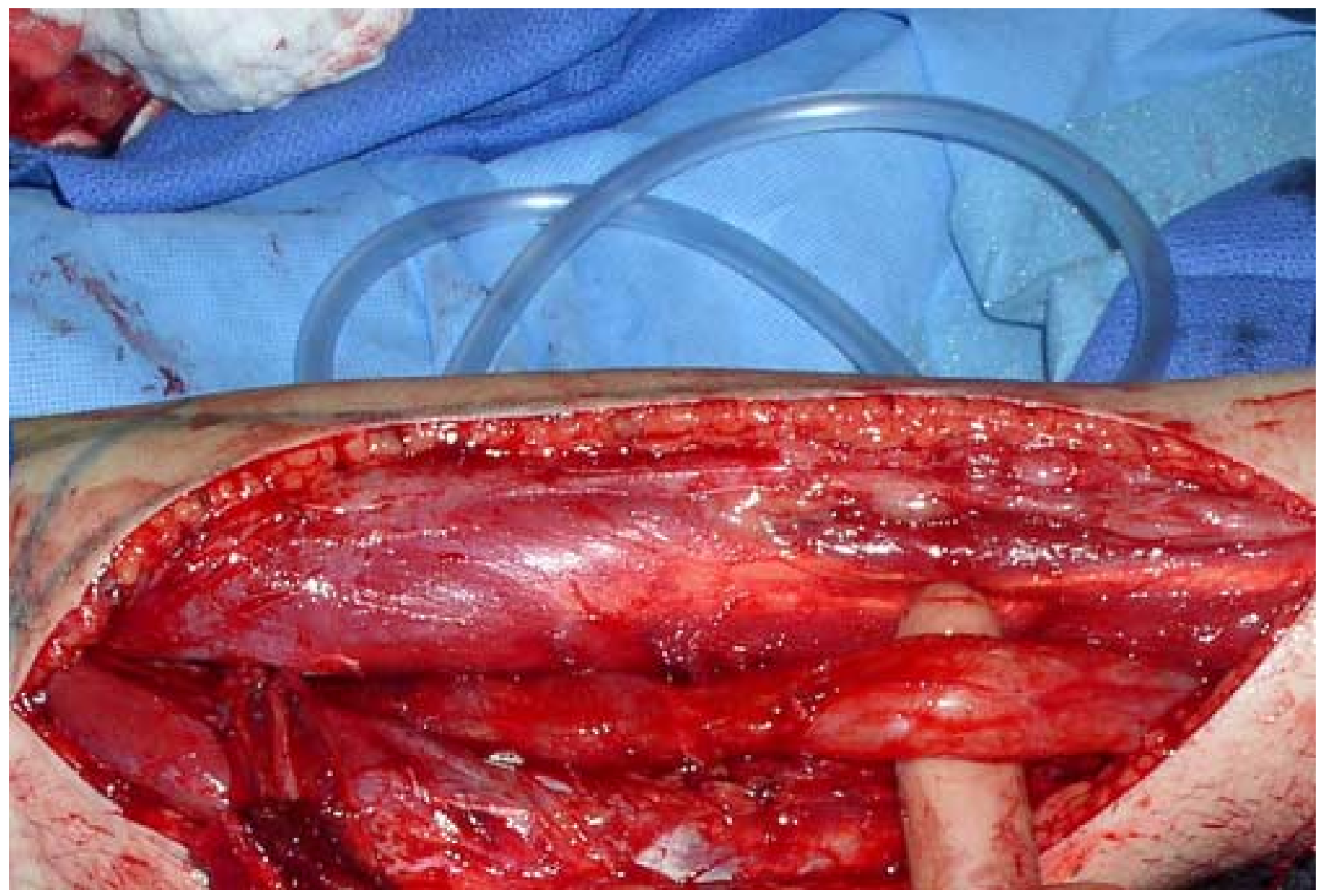


Figure 8
Click here to download high resolution image

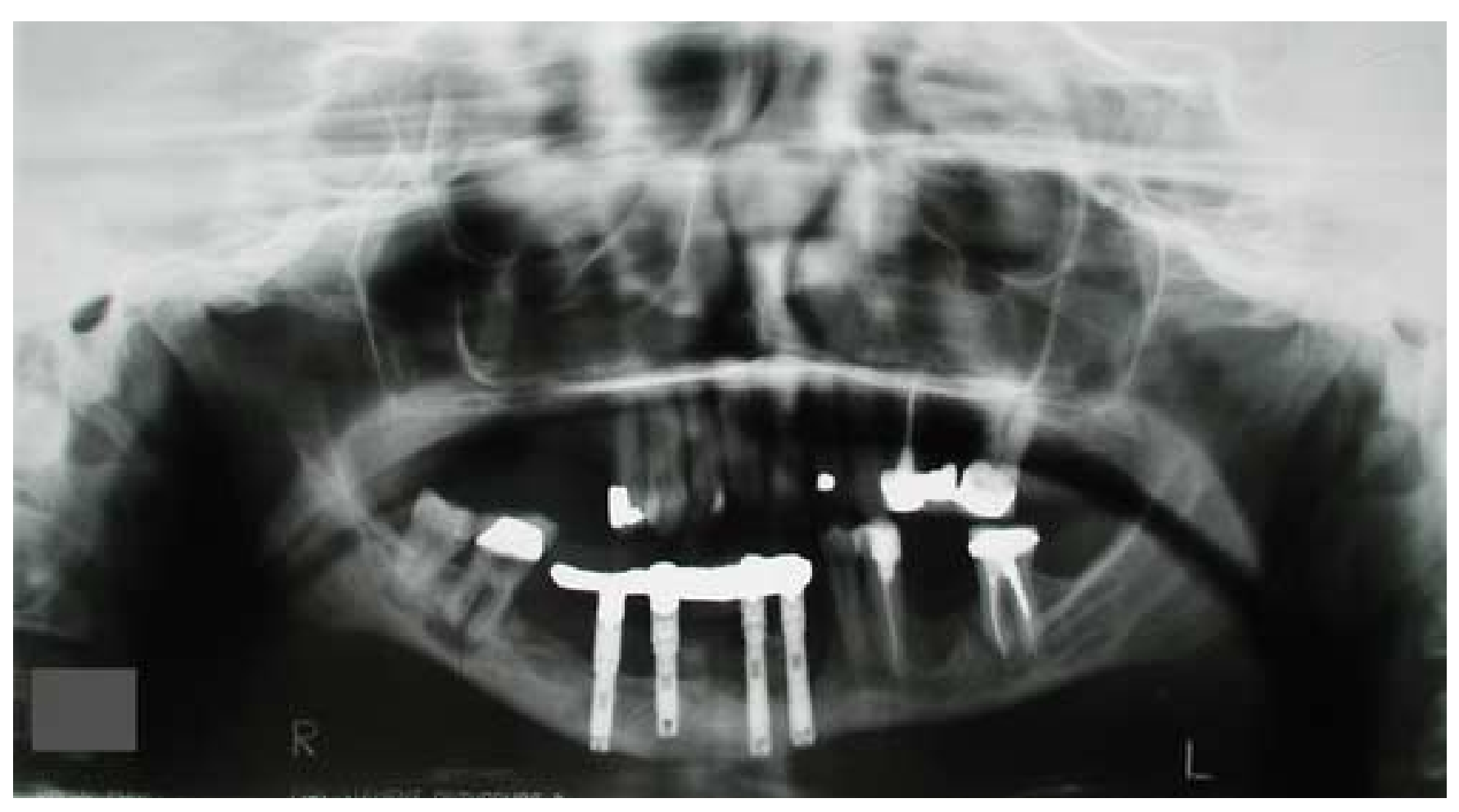




\section{Table 1: Diagnostic Criteria for Neurofibromatosis 1}

(1987 National Institutes of Health Consensus Development Conference')

The diagnostic criteria for NF-1 are met in an individual if two or more of the following are found:

- Six or more café-au-lait macules over $5 \mathrm{~mm}$ in greatest diameter in prepubertal individuals and over $15 \mathrm{~mm}$ in greatest diameter in postpubertal individuals.

- Two or more neurofibromas of any type or one plexiform neurofibroma.

- Freckling in the axillary or inguinal region.

- Optic glioma.

- Two or more Lisch nodules (iris hamartomas).

- A distinctive osseous lesion such as sphenoid dysplasia or thinning of long bone cortex with or without pseudarthrosis.

- A first-degree relative (parent, sibling, or offspring) with NF-1 by the above criteria.

Note: Although not part of the NIH Consensus Development Conference recommendations, it has been recommended that infants with multiple café-au-lait macules should be reassessed annually until age 10 years for the development of additional diagnostic criteriaii. 
'Neurofibromatosis. NIH Consens Statement 1987 Jul 13-=15; 6:1-19.

ii Gutman DH, Aylsworth A, Carey J, Korf B, Marks J, Pyeritz RE, et al. The diagnostic evaluation and multidisciplinary management of neurofibromatosis 1 and neurofibromatosis 2. JAMA 1997;278:51-7. 